\title{
EFFECT OF CELERY (APIUM GRAVEOLENS) ON THE REDUCTION OF BLOOD PRESSURE: A SYSTEMATIC REVIEW
}

\author{
Elma Marsita \\ Masters Program in Midwifery, School of Health Polytechnics, \\ Ministry of Health, Semarang
}

\begin{abstract}
Background: High blood pressure, also called hypertension, is one of the most common causes of early death in symptom-free adults. About 75 to $80 \%$ of the world population use herbal medicines for primary health care because of their better acceptability with human body and lesser side effects. Celery or Apium graveolens is a plant from the family of Apiaceae that has been used to lower blood preasure. This study aimed to review systematically the effect of Apium graveolens on the reduction of blood pressure.

Subjects and Method: This was a systematic review. The theme of this study was the benefits of non-pharmacological treatment of celery extract in hypertensive experimental animal. A total of 6 articles were obtained from Science Direct, CINAHL, Pub Med, Elsevier (SCOPUS), and Pro Quest databases. Articles were specified based on inclusion and exclusion criteria. The inclusion criteria were articles published in English, time period around 2008 to 2018, quantitative study, non-duplicate articles published by Science direct, CINAHL, Pub Med, Elsevier (SCOPUS), and Pro Quest, and obligated to the objective of this study.

Results: Celery extract had a significant effect to help lower the blood pressure in hypertension. The celery was extracted with ethanol, hexane, ethyl acetate, methanol, and pure water. All study were used laboratory experiments method with experimental animal. Most of them showed hypotensive effects through bradycardia and vasodilation from the administration of celery extract.

Conclusion: Celery extract has a significant effect to help lower the blood pressure in experimental animal with hypertension.
\end{abstract}

Keywords: celery, Apium graveolens, blood pressure, hypertension, hypotensive effect

\section{Correspondence:}

Elma Marsita. Masters Program in Midwifery, School of Health Polytechnics, Ministry of Health, Semarang, Central Java. Email: elmamarsita93@gmail.com.

Mobile: 089693479630.

The 5th International Conference on Public Health

Best Western Premier Hotel, Solo, Indonesia, February 13-14, 2019 | 618

https://doi.org/10.26911/theicph.2019.05.17 